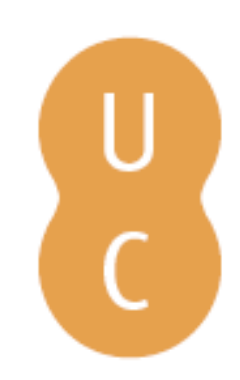

\title{
nombalina
}

\section{A pré-existência do Cardo/ Decumanus no plano pombalino e a sua herança na Lisboa contemporânea}

\author{
Autor(es): $\quad$ André, Paula \\ Publicado por: Associação Portuguesa de Estudos Clássicos; Centro de Estudos \\ URL $\quad$ URI:httente: $\quad$ URdl.handle.net/10316.2/31569 \\ DOI: DOI:http://dx.doi.org/10.14195/978-989-8281-69-2_23 \\ Accessed : $\quad$ 26-Apr-2023 13:49:36
}

A navegação consulta e descarregamento dos títulos inseridos nas Bibliotecas Digitais UC Digitalis, UC Pombalina e UC Impactum, pressupõem a aceitação plena e sem reservas dos Termos e Condições de Uso destas Bibliotecas Digitais, disponíveis em https://digitalis.uc.pt/pt-pt/termos.

Conforme exposto nos referidos Termos e Condições de Uso, o descarregamento de títulos de acesso restrito requer uma licença válida de autorização devendo o utilizador aceder ao(s) documento(s) a partir de um endereço de IP da instituição detentora da supramencionada licença.

Ao utilizador é apenas permitido o descarregamento para uso pessoal, pelo que o emprego do(s) título(s) descarregado(s) para outro fim, designadamente comercial, carece de autorização do respetivo autor ou editor da obra.

Na medida em que todas as obras da UC Digitalis se encontram protegidas pelo Código do Direito de Autor e Direitos Conexos e demais legislação aplicável, toda a cópia, parcial ou total, deste documento, nos casos em que é legalmente admitida, deverá conter ou fazer-se acompanhar por este aviso.

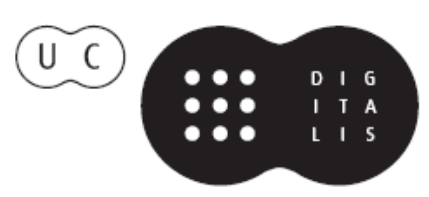




\section{Espaços e Paisagens}

Antiguidade Clássica

e Heranças Contemporâneas

Vol. III

Francisco Oliveira, Jorge Oliveira e Manuel Patrício

IMPRENSA DA UNIVERSIDADE DE COIMBRA 


\title{
A PRÉ-EXISTÊNCIA DO CARDO / DECUMANUS NO PLANO POMBALINO E A SUA HERANÇA NA LISBOA CONTEMPORÂNEA
}

\author{
PAUla ANDRÉ \\ Departamento de Arquitectura e Urbanismo
}

ISCTE

\begin{abstract}
Cardo / Decumanus in the $18^{\text {th }}$ century Pombaline Plan for Lisbon and their inheritance in contemporary Lisbon.

The logic of Pombal's Plan for the reconstruction of Lisbon after the earthquake of 1755 , is set in the enlightened and hygienist thought of Ribeiro Sanches and his work Tratado de conservaçam da saude dos povos (1756). According to this work, based on the classic thought of Vitruvius, "the Romans built the (main) streets with the same width of military lanes, or royal roads; they led to city gates or the squares: the second type of streets was narrower and corresponded to the width of the paths that came from the military lanes". This hierarchy is present in Pombal's Plan, carried out by the engineers/urbanists, composed of main streets and secondary streets, and shows that city planning never forgot the two pre-existing structural axis, the Rua Nova d'El Rei - Cardo - and the Rua Nova dos Mercadores - Decumanus denouncing its classical references. The regularity of this plan, and its imbued classical tradition, is a landmark of Lisbon, which we see today elevated to the category of monument.
\end{abstract}

Keywords: Cardo-Decumanus, Lisbon, Pombal's Plan.

Palavras-chave: Cardo-Decumanus, Lisboa, Plano Pombalino.

A Lisboa conquistada por D. Afonso Henriques era já constituída pelo conjunto amuralhado (Cerca Moura) e pelos bairros extramuros. No reinado de D. Dinis, executam-se os primeiros aterros na zona do esteiro, de modo a permitir a construção das Tercenas Reais e Estaleiros, junto à escarpa de S. Francisco, o que denota já uma descida e um avanço da cidade em relação ao rio. D. Dinis constrói ainda a segunda muralha da cidade, a primeira da ribeira, com o intuito de proteger os novos núcleos que entretanto se expandiram, como o da Baixa (a ocidente) e o de Alfama (a oriente). Contudo, essa muralha não chegou a ser concluída e efectivamente só no reinado de D. Fernando, em 1373 , com a construção de uma nova muralha, mais próxima do rio ${ }^{1}$, essas novas áreas urbanas passaram a ficar englobadas no seu interior.

No século $\mathrm{XV}$, será nesta nova ribeira que se irá desenvolver todo um conjunto de equipamentos relacionados com expansão ultramarina: a Casa de

1 “Quando D. Diniz construiu a sua muralha na Ribeira, era a rua Nova uma praia ou um 
Ceuta, a partir de 1434, e a Casa dos Escravos, em 1486. D. Manuel I decidiu descer da Alcáçova ${ }^{2}$, iniciar novos aterros na ribeira e construir o Paço sobre a casa da Índia, Mina e Guiné. O terreiro, antes esteiro, praia e ribeira, tomou então a designação de Terreiro do Paço, gerando-se ali um palco privilegiado da cidade e da sua imagem.

A Norte da cidade existia um outro grande vazio, o Rossio de Lisboa Rossio ou Ressio que, segundo Luis de Vasconcelos, na sua obra Etnografia Portuguesa, tem origem no adjectivo latino residuus, que significa «remanescente» - onde se realizavam feiras ${ }^{3}$. Este espaço seria marcado, a Norte, pelo paço dos Estaus, mandado construir por D. Pedro, e, a Nascente, pelo conjunto do Hospital de Todos os Santos, obra encomendada por D. João II. Esses dois grandes vazios da cidade de Lisboa, a ribeira tornada Terreiro do Paço e o Rossio, exibidos na gravura de Lisboa Olissipo quae nunc..., que G. Braunio publicou no Vrbium Praeciparum Mundi Theatrum Quintum em 1598 , foram sempre polos estruturadores do desenvolvimento urbano, palcos preferenciais dos diferentes tempos, mantendo essa identidade mesmo depois do terramoto no plano pombalino. Para além destes dois grandes vazios, a cidade de Lisboa foi estruturada por outros dois eixos de desenvolvimento, duas ruas que também se mantiveram estruturantes no plano pombalino: a Rua Nova, eixo paralelo ao rio, e a Rua Nova d'El Rei, eixo perpendicular ao rio.

A Rua Nova, eixo paralelo e aberto ao rio, provavelmente já existiria no reinado de D. Dinis. Encontramo-la na regularização e ampliação da mesma Rua Nova em 1294, empreitada que obrigou ao derrube das casas "para que a rua fique de 8 braças, como chamou a atenção Helder Carita na sua obra Lisboa manuelina e formação de modelos urbanísticos da época moderna (1495-1521). No séc. XV, a Rua Nova passa a ter a designação de Rua Nova dos Mercadores, sendo também referida ainda nesse século como Praça dos Homens de Negócios. As primeiras notícias do projecto de calcetamento da Rua Nova de Lisboa "constam de uma carta de D. João II, datada de Novembro de 1482, onde o rei (...) determinou, como trabalho prévio, a execução de uma planta «pyntada em papell», para melhor poder estudá-la e emitir o seu parecer"4. Após a viagem ao Porto em 1483, D. João II, tendo apreciado na

aterro de formação recente, que tiveram de alargar contra o rio para a fundação do muro. Mais tarde, já no aterro que pouco a pouco se havia conquistado ao Tejo, poude D. Fernando fundar a sua muralha, à frente da de D. Diniz, contra o mar", A. Silva 1987129.

${ }^{2}$ Esta descida da cidade em relação ao rio traduz-se também na deslocação de alguns centros sociais, nomeadamente a substituição do Largo da Sé e da Madalena pela Praça do Pelourinho Velho, na extremidade Oriental da Rua Nova dos Mercadores, que adquire uma nova centralidade.

3“A Feira da Ladra trocara, no decurso de quatrocentos, o Largo da Feira, que dela tomou nome, junto da entrada do Castelejo, pelo Rossio de Santa Justa, onde permanecerá até ao Terramoto de 1755"; desde finais do séc. XV, esta feira realizava-se todas as $3^{\text {as }}$ feiras defronte do Hospital Real de Todos os Santos, "na qual, de mistura com as manufacturas da terra, começavam a aparecer produtos vindos do Norte de África e do Oriente, em primeira ou segunda mão", I. Moita 1983 9, 14.

${ }^{4}$ I. Gonçalves 1995105. 
Rua Nova a qualidade do trabalho e da pedra utilizada, ordenou que em Lisboa fosse utilizado igual processo e a pedra dali trazida ${ }^{5}$. Seria assim aprovada "a despeza orçada para o calcetamento da Rua Nova Grande dos Mercadores, devendo empregar-se n'essa obra pedra do Porto [granito], «por que a outra dapnase na maneira que vêdes ${ }^{6}$. Para além destes melhoramentos, há uma preocupação com o reordenamento alinhado do centro da cidade, com a regularização, o alinhamento das ruas, denotando uma estética da linha recta, presente em várias cartas para o Senado de Lisboa, como podemos verificar na referência do secretário António Carneiro: «...como os (esteios) da rua nova dereitos e muy bem obrados e ainda nalguns lugares em que convem the seja dado tanto chão como convinha para todas as casas ficarem yguais e por cordel e que hua não saya mais que outra...»" o facto de na Rua Nova dos Mercadores ainda existirem "casas construídas com materiais menos nobres, como a madeira, (...) deu um prazo de um ano

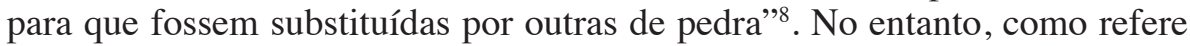
Walter Rossa, "já em 1462 D. Afonso V tentou impor que as casas da Rua Nova de Lisboa fossem feitas sobre arcos de cantaria e daí até ao telhado em alvenaria de pedra e cal, sem tabuados" ". Seria através da acção de D. Manuel que a referida rua passaria a ter "um notável perfil urbano com edifícios de habitação de cinco andares, onde o piso térreo era ocupado pelas mais bem fornecidas lojas de toda a Europa em matérias-primas e objectos provenientes do Oriente e de África, autênticos «gabinetes de curiosidades»" 10 . Em meados do séc. XVI, a Rua Nova divide-se em duas partes: a ocidente passa a ter o nome de Rua Nova dos Mercadores e a oriente de Rua Nova dos Ferros, com grades de ferro dispostas longitudinalmente. Mais tarde, a denominação de Rua dos Ferros estende-se a toda a rua, sendo esta a sua designação em 1755. Esta rua, porém, era conhecida simplesmente como Rua Nova.

A Rua Nova d'El-Rei, eixo perpendicular ao rio, mandada abrir por D. João I, é referida no século XIV como o rego, passando depois a ser mencionada como Rua do Cano Nova. Quando D. Manuel I prolonga a Rua Nova d'El Rei, o Rossio passou a ficar ligado à zona da Ribeira, tendo sido necessário demolir construções para que ficasse alinhada. A partir de meados do séc. XVI, esta rua passa a ser mencionada de Rua da Ourivesaria do Ouro ou dos Ourives do Ouro, sendo essa a sua designação em 1755. À semelhança do que tinha sido feito com a Rua dos Ourives da Prata ${ }^{11}$, as obras de alargamento da Rua

${ }^{5}$ W. Rossa 1999261.

${ }^{6}$ E. Oliveira 1885 384. "Quando D. João II morreu, em finais de Outubro de 1495, treze anos volvidos após o seu início, ignoramos o adiantamento dos trabalhos, mas sabemos que estavam ainda longe do fim. D. Manuel retomou o empenhamento do seu antecessor", I. Gonçalves 1995107.

${ }^{7}$ H. Carita 200041.

${ }^{8}$ I. Gonçalves 1986170.

${ }^{9}$ W. Rossa 1999261.

10 P. Pereira 200643.

11 «esta obra tem consequencias mui uteis, porque cresce a cidade em formosura, e para a nobreza fica facil a serventia que pela Padaria é tão dificultosa (...)», in Consulta da Câmara 
dos Ourives do Ouro, que ficaria com quarenta palmos de largura, de modo a ser "a mais pública e principal"12, prosseguem com D. Pedro II. Esta obra é mencionada em carta do Secretário de Estado, Pedro Sanches de Farinha, de 13 de Setembro de 1686: “(...) e também ordena que V. S ${ }^{a}$, vendo, com os ministros do senado, o quanto se necessita de que a Rua dos Ourives do Ouro se largue, por ser o concurso de toda a cidade, e por esta causa haver sempre n'ella contendas nas passagens por não caberem dois coches por ella, se trate dos effeitos que pode haver para esta obra que é tanto em utilidade do commum"13.

Aimportância da Rua Nova d'El Rei (cardo) e da Rua Nova dos Mercadores (decumanus), eixos e pólos estruturadores do fazer e do traçado urbano, fica também patente nas referências feitas nas mais diversas fontes.

Cristovão Rodrigues de Oliveira, em inícios do século XVI, refere que do "Rossio, querendo ir para o mar, entram na rua Nova d'El-Rei, comprida e direita rua, que vai dar na grande rua Nova dos Mercadores, que por ser na principal parte da cidade e junto do mar ao longo dele, é lugar onde concorrem todos os mercadores e toda a mais gente de trato, que tem de comprido duzentos passos e de largo vinte; e sabe-se que rende em alugueres de casas oitenta mil cruzados"14. Também o Padre Sande referiu, em 1584, que "há nesta rua, além d'outras coisas, edifícios admiráveis, de tantos pavimentos e com tantos inquilinos, que não se conhecem uns aos outros nem de cara nem de nome"15. Damião de Góis menciona que do Rossio, "passando a Praça Nova do Rei, que transborda de entalhadores, joalheiros, ourives, cinzeladores, fabricantes de vasos, artistas da prata, de bronze e de ouro, bem como de banqueiros, cortando á esquerda, chegaremos a uma outra artéria que tem o nome de Rua Nova dos Mercadores, muito mais vasta que todas as outras ruas da cidade, ornada, de um lado e de outro, com belíssimos edifícios" "16. E Francisco Javier Pizarro Gómez refere também que "Filipe II assistiu a várias representações teatrais alegóricas do dia da entrada oficial do monarca, realizadas na Rua Nova"17, ganhando a rua a dimensão de palco por excelência da cidade.

Concordamos com José Custódio Vieira da Silva quando refere, por um lado, que as "cidades da Idade Média (...) se constituem como continuum em relação aos modelos da arquitectura e urbanismo da Antiguidade grega e romana", e, por outro, que na "Lisboa medieval houve três momentos decisivos de alargamento estruturado: o primeiro, em tempos do rei D. Dinis e

ao Rei de 23 de Novembro de 1676, Liv IV de Cons. e Decr. Do Principe D. Pedro, fl. 386 (AHCML), citado por E. Oliveira 1885 173: “em que se tornou necessário derrubar vinte e seis «moradas de casas»". H. Murteira 199988.

${ }^{12}$ H. Murteira 199992 e 85, respectivamente.

${ }^{13}$ H. Murteira 199985.

${ }^{14}$ C. Oliveira 198719.

${ }^{15}$ C. Oliveira 1987103.

${ }^{16}$ D. Góis 200216.

${ }^{17}$ F. Pizarro Gómez 1987127. 
D. Fernando; o segundo com D. João I até à regência de D. Pedro; o terceiro, sob D. João II e D. Manuel"18.

Há uma preocupação pré-pombalina com a regularidade e a simetria, presente em todas as determinações. Tal como refere Helena Murteira, a propósito de um pedido de construção de um palheiro na Praça da Ribeira, a 6 de Março de 1704, uma Consulta da Câmara ao Rei, menciona que “(...) o Senado, por decretos e resoluções de V. Majestade está dispendendo e dispendeu considerável fazenda em alargar as ruas, (...) cordeamentos regulares que devem ter as ruas para formosura da cidade" 19 . E denotando exactamente o mesmo tipo de preocupação em 1751, a Coroa decide que o arquitecto camarário, Eugénio dos Santos, deveria estar presente em todas as vistorias das obras da cidade e o Presidente do Senado defende: "não pode haver vistoria alguma que não respeite ao ornato e symetria da cidade"20.

Com o terramoto, maremoto e incêndio de 1755 , as construções desta zona da cidade ficaram destruídas e Sebastião José de Carvalho e Melo, Secretário de Estado dos Negócios Estrangeiros e da Guerra, encarrega Manuel da Maia, o mestre de campo-general e engenheiro-mor do Reino, de estudar propostas para a reconstrução da cidade de Lisboa. Entre 4 de Dezembro de 1755 e 19 de Abril de 1756, este engenheiro redige a sua Dissertação sobre a renovação da Cidade de Lisboa, na qual apresenta cinco modos alternativos, devidamente justificados, para a reconstrução. O futuro Marquês de Pombal opta pelo quarto modo, ou seja, a reconstrução in loco com um novo plano. São então propostos seis novos planos, dos quais é eleito o do capitão Eugénio dos Santos, arquitecto do Senado. Este era o mais "abstracto e geométrico", em que as praças do Rossio e do Terreiro do Paço eram "regularizadas e redefinidas na sua forma e orientação" "21. Na proposta de Eugénio dos Santos, os dois grandes vazios pré-existentes parecem adquirir a dimensão sagrada atribuída normalmente aos espaços das igrejas que, por sua vez, não são repostas nos locais préexistentes $^{22}$, mas são assimiladas na ordem imposta pela malha urbana. É por esta quase sacralização do secular que a lógica iluminista começa por estar presente no projecto pombalino da Baixa de Lisboa, na qual se enquadra também o pensamento esclarecido e higienista de Ribeiro Sanches, presente na sua obra Tratado de conservaçam da saude dos povos (1756). Ribeiro Sanches, chamando a atenção para a conveniência em consultar os médicos para a fundação de qualquer povoação, refere que se deve ordenar e "fabricar ruas largas e diretas que se terminem nas grandes praças" 23 . Tendo por base

18 J. Silva 200636.

${ }^{19}$ Consulta da Câmara ao Rei de 6 de Março de 1704, Liv ${ }^{\circ}$ XIX de Cons. e Decr. de D. Pedro II, fl. 84 (AHCML), citado por E. Oliveira 1885 232-233. M. Murteira 1999 69-79.

${ }^{20}$ Consulta da Câmara ao Rei de 17 de Janeiro de 1754, Liv $^{\circ}$ V de Cons. e Decr. de D. José I, fl. 25 (AHCML), citado por E. Oliveira 1885 232,233. M. Murteira 1999 69-79.

${ }^{21}$ M. Teixeira, M. Valla 1999 290-291.

${ }^{22}$ Embora José Augusto França refira que Eugénio dos Santos tenha tido remorsos “de ter lesado as igrejas da Baixa com os seus planos, mais atentos aos interesses novos do urbanismo que a outros, tradicionais da religião". J. França 1987107.

${ }^{23}$ A. Sanches 175648. 
uma raiz clássica fundamentada em Vitrúvio e Alberti, Sanches relembra que "os Romanos fazião as ruas das cidades da mesma largura, que tinhão as vias militares, ou estradas reaes; terminavão-se nas portas dellas, ou nas praças: a segunda sorte de ruas era mais estreita, e conrespondia a sua largura à dos caminhos de travessa, que sahião das vias militares" ${ }^{24}$, hierarquia viária que se aproxima claramente da lógica que encontramos no plano da Baixa de Eugénio dos Santos. É já sob a direcção de Eugénio dos Santos que, a 12 de Junho, em substituição da Aula do Paço da Ribeira, se constitui a Casa do Risco das Obras Públicas. É na Casa do Risco que Eugénio dos Santos ${ }^{25}$ elabora o projecto da futura Praça do Comércio, redesenhando o espaço pré-existente com a construção de aterros, mantendo a abertura a Sul, para o rio Tejo, e pontuando-a com a estátua equestre de D. José I. A Praça do Comércio tem uma espacialidade permanente que promove a descodificação da representação perspéctica, procurando entender a maneira de representar, de expressar e de apresentar o espaço. Os arquitectos/engenheiros militares do Reino desenharam-na aplicando a matriz da linha recta, absorvendo a lição da composição urbana das missões jesuíticas e à maneira dos arquitectos cenógrafos, podendo ser olhada como um desenho arquitectónico para uma perspectiva de cena. Quando percorremos a praça, vemos esse espaço como a scaenae frons dos teatros romanos e quando estamos no seu centro, lugar da skene e da orchestra, somos simultaneamente actores e espectadores. O modo particular de articular espaço fechado e espaço aberto, abrindo um dos lados da praça ao rio, sugere, simultaneamente, que se olhe a praça como espectador e que se use a praça como actor.

Pedro Vieira de Almeida refere que o "Pombalino surge como uma estrutura imagética articulada não em edifícios ou objectos urbanos particularmente significativos, nem em frentes-fachada particularmente ricas, mas em espaços urbanos, espaços-rua e espaços-praça" ${ }^{26}$. Os arquitectos/engenheiros de Pombal, contudo, também não terão certamente esquecido "as plantas de tudo o que ha celebre no Mundo, e modellos de todas as Igrejas, e mais famosos Palacios de Roma"27, que D. João V mandava vir da cidade pontificia e reunia no salões do Paço da Ribeira. Se no Plano Regulador para Roma de Sixto V, elaborado por Domenico Fontana, as vias traçadas unem edifícios notáveis, no Plano de Pombal, elaborado pelos engenheiros/urbanistas, onde contracenam ruas principais e ruas secundárias, as vias unem os dois grandes vazios notáveis: Rossio e Terreiro do Paço.

O plano pombalino é também caracterizado pelos espaços intermédios, pelas conexões e pelo modo como se justapõem os seus elementos, ou seja, o modo como a moderna plataforma se liga com a antiga malha urbana da

${ }^{24}$ A. Sanches 175648.

${ }^{25}$ Coadjuvado pelo tenente-coronel húngaro Carlos Mardel, arquitecto dos Paços Reais e das Ordens Militares.

${ }^{26} \mathrm{P}$. Almeida 1973457.

${ }^{27}$ F. Silva 1750267. 
cidade $^{28}$. É a regularidade de todo o plano da Baixa de Lisboa que se torna num excelente meio de comunicação da imagem da cidade. É a matriz da linha recta como fundamento e espírito de regularidade e uniformidade que serve de base tanto à arquitectura como ao desenho da cidade. O que mostra que o fazer da cidade passou pelo fazer/desenhar os vazios, não esquecendo nunca os dois eixos estruturantes, a Rua Nova d'El Rei - cardo - e a Rua Nova dos Mercadores $^{29}$ - decumanus - , denunciando uma ancestralidade clássica.

A estética da linha recta revela-se uma matriz fruto não só do desejo, mas também da regra e, mais interessante, da prática. A atenção ao lugar, ao sítio, característica da arquitectura e do desenho urbano português, advém precisamente não de um modelo, mas sim da pré-existência de um modo de fazer. E é exactamente porque existe essa matriz fundamentada numa prática que o fazer urbano é competência dos engenheiros militares, uma competência erudita e pragmática e que se revelaria programática. É a tradição da estética da linha recta no projecto arquitectónico e no projecto urbano que vemos elevada à categoria de monumento.

\section{Anexos}

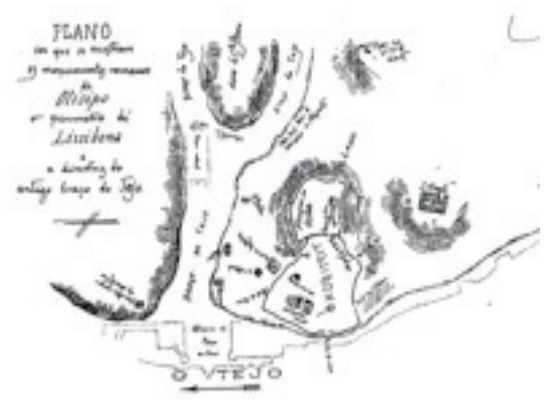

Fig.1. Planta de Lisboa anterior ao séc. XII segundo Júlio de Castilho (1893)

28 “Não posso deixar de acrescentar aqui ser muito preciza huma especial attenção na elleição das pessoas que hajão de ter por sua conta a execução desta difficultosa obra da renovação de Lisboa baixa, para a guiarem livre dos embaraços que se poderão encontrar, ou incluir entre a correspondencia do antigo com o moderno, no cazo de haver alguma commutação do velho, como o novo que he aonde consiste a mayor difficuldade" (Dissertação de Manuel da Maia, III parte). J. França 1987323.

29 "Plano de 12 de Junho de 1758; 42 - Em primeiro lugar: devendo a antiga Rua Nova dos Ferros, e antiga Rua da Confeitaria ser reduzidas a huma só, e unica Rua, com a denominação de Rua Nova de ElRey: nos terrenos, que antes ocupavão as referidas duas Ruas; pareceu, que ou haverá o espaço, que baste, ou não faltará muito para se alinhar a nova Rua, que deve cortarse com a largura de sessenta palmos por fora dos edificios, que formarem o lado Septentrional do Terreiro do Paço, na forma acima declarada. (Belém, 12 de Junho de 1758, Sebastião José de Carvalho e Melo)". J. França 1987337. 


\section{PAUla André}

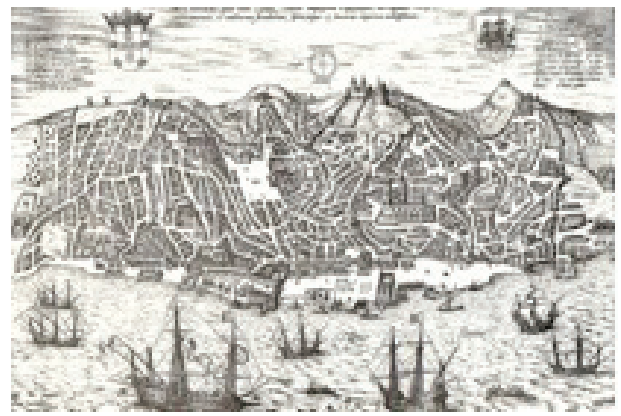

Fig.2. Olissipo quae nunc..., gravura em cobre, Georgius Braunius,

Vrbium Proecipuarum Mundi Theatrum Quintum, 1598

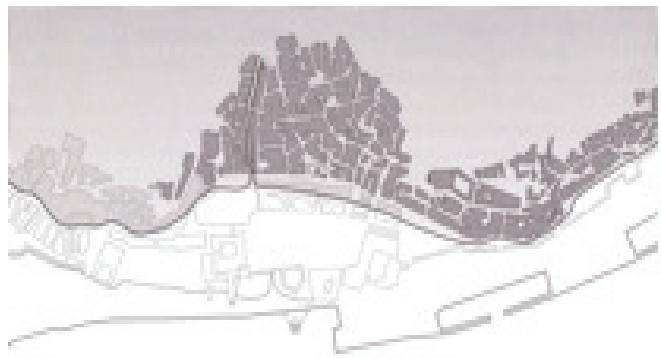

Fig.3. Traçado conjectural da praia medieval na segunda metade do séc. XIII; desenho de José António; C. Caetano 200434

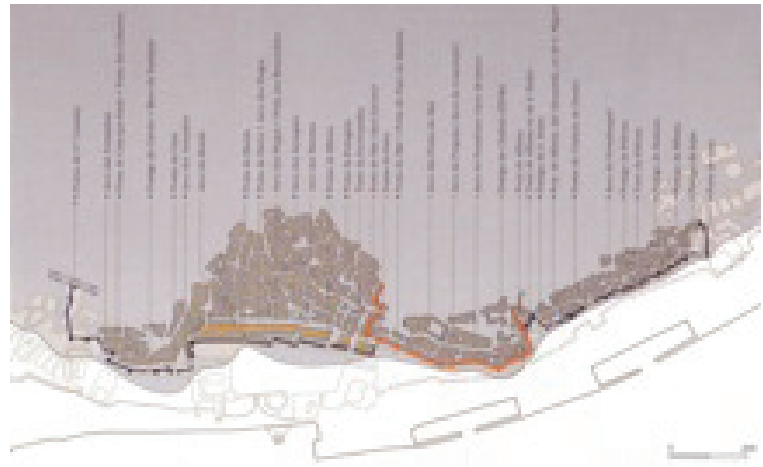

Fig.4. Portas e postigos das Cerca Moura e Fernandina; desenho de José António; vermelho - Cerca Moura; amarelo - Muralha de D. Diniz; azul - Muralha de D. Fernando; Linha cinza - traçado conjectural da linha de praia do fim do séc. XIV; C. Caetano 200437 


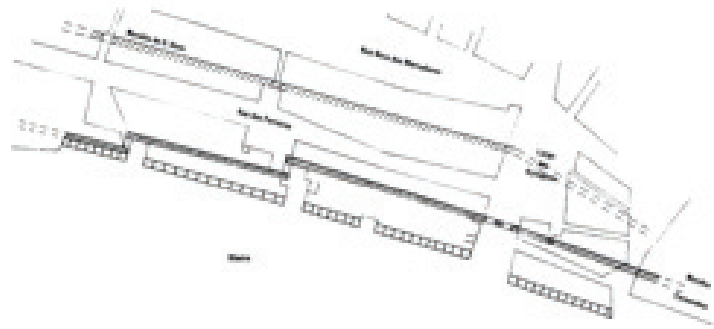

Fig.5. Planta de localização do conjunto da Ribeira no Terreiro do Paço, com base na planta de João Nunes Tinoco de 1650. H. Carita 199965

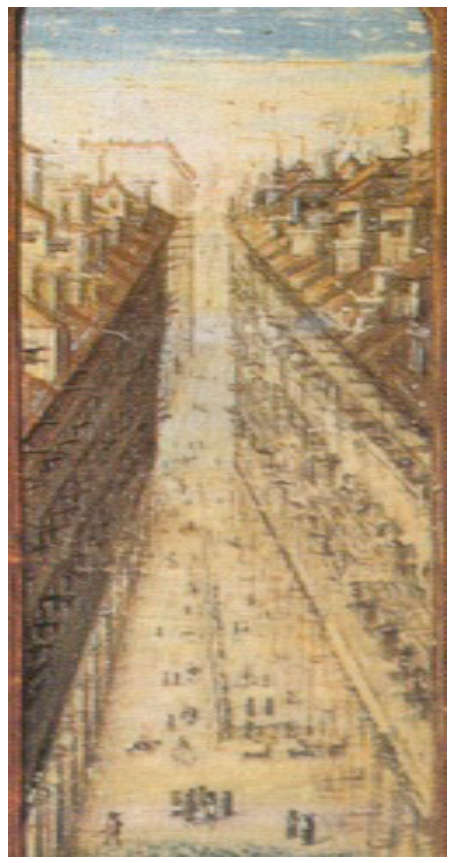

Fig.6. Iluminura em pergaminho, Livro de Horas [dito] de D. Manuel, Séc. XVI, fl. 130, MNAA. 


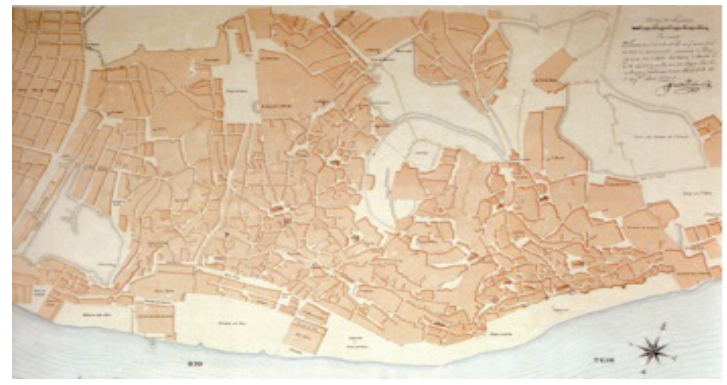

Fig.7. Planta da Cidade de Lisboa, gravura, João Nunes Tinoco, 1650, Museu da Cidade, Lisboa

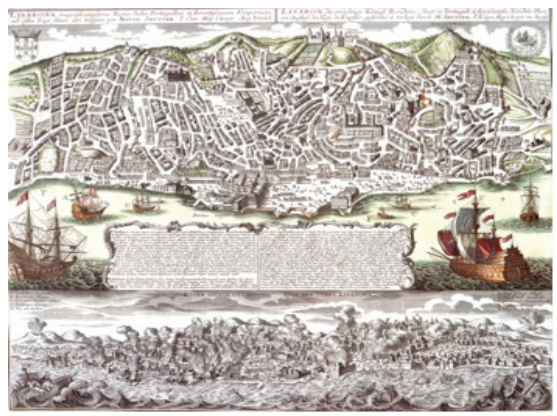

Fig.8. Lisboa, antes e depois do terramoto de 1755, representação bipartida inspirada pela perspectiva quinhentista de Braunio Matthaus Seuter

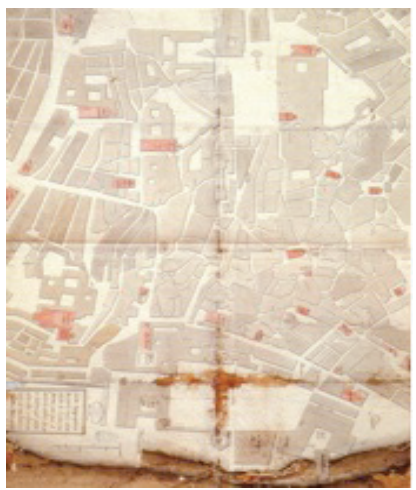

Fig.9. Carta topográfica da parte mais arruinada de Lisboa na forma, em que se achava antes da sua destruição para sobre ela se observarem os melhoramentos necessários, Manuel da Maia; Gabinete de Estudos de Arqueologia e Engenharia Militar. W. Rossa 200425 


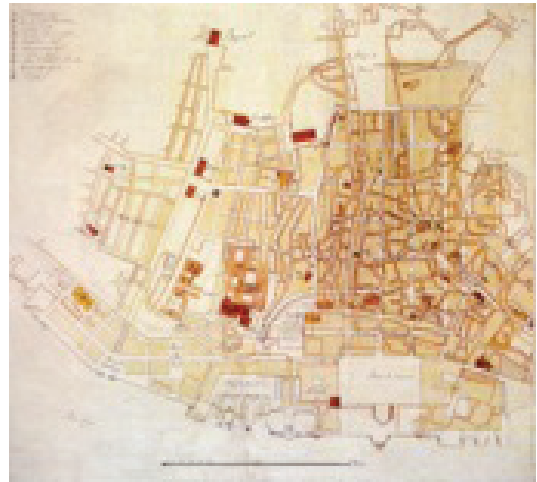

Fig.10. Carlos Mardel e Eugénio dos Santos, um dos dois estudos, para o plano-piloto da Baixa-Chiado, 1758; Instituto Geográfico Português www.igeo.pt. W. Rossa 200429

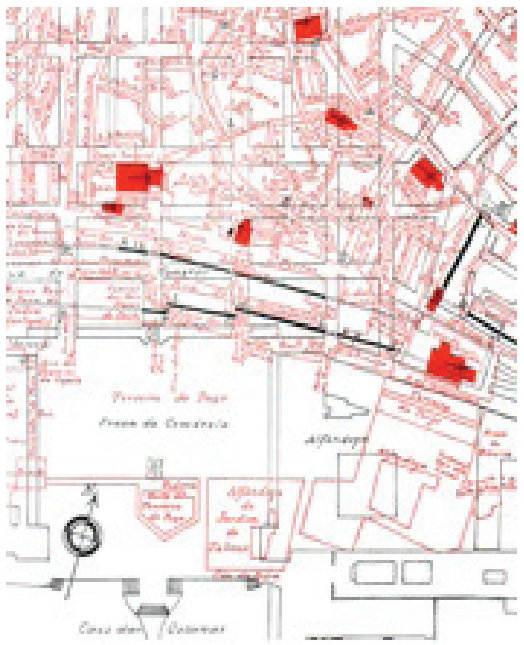

Fig.11. Fragmento da Planta de Lisboa; O traçado e dizeres a preto correspondem à actualidade; o traçado e dizeres a vermelho correspondem à Lisboa anterior ao terramoto de 1755 . A. Silva 1987 vol. 1 


\section{PAUla André}

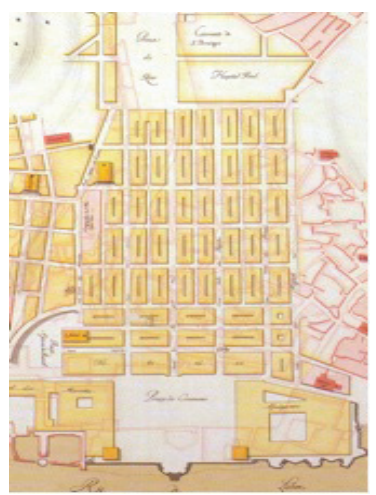

Fig.12. Nova Lisboa, cópia da denominada planta número 5(?). Desenho a tinta-da-china, aguarelado a carmim e a amarelo in Monumentos. Lisboa, $\mathrm{n}^{\circ}$ 21, Setembro, 200468

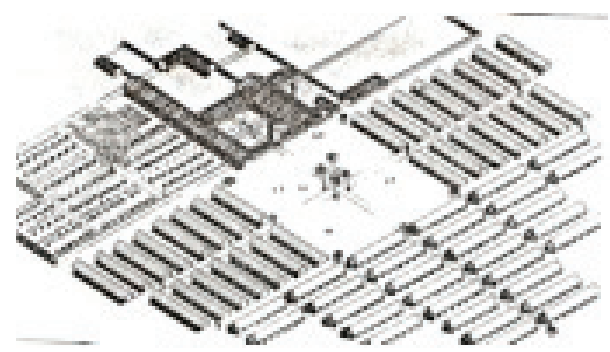

Fig.13. Missão Jesuítica San José de Chiquitos, Fr. Felipe Suarez; Fr. Dionisio Ávila, 1698, Bolívia. G. Rocha Filho 1995

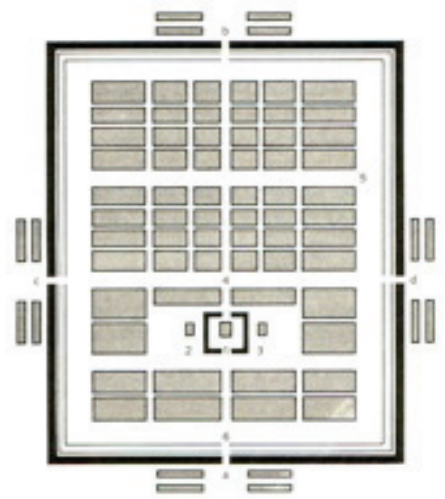

Fig.14. Esquema do castrum romano: a-b. Decumano; c-d. Cardo; 1. Praetorium; 2 e 3. Tribunal, questores; 4. Tribunos; 5. Cavalaria; 6. Tropas auxiliares. G. Argan 200396 


\section{Bibliografia}

P. Almeida (1973), “A Arquitectura do século XVIII em Portugal. Pretexto e argumento para uma aproximação semiológica", Bracara Augusta. Revista Cultural de Regionalismo e História da Câmara Municipal de Braga. Braga, nº 27.

G. Argan (2003), Historia da Arte Italiana. Da Antiguidade a Duccio. São Paulo. vol. 1.

C. Caetano (2004), A Ribeira de Lisboa. Lisboa.

H. Carita (1999), Lisboa manuelina e a formação de modelos urbanisticos da época moderna (1495-1521). Lisboa.

H. Carita (2000), "Reforma Urbanística da Lisboa Manuelina. Início da escola moderna de arquitectura", História 40 36-45.

J. A. França (1987), Lisboa Pombalina e o Iluminismo. Lisboa.

D. Góis (2002), Elogio da Cidade de Lisboa. Lisboa.

I. Gonçalves (1986), "Posturas Municipais e Vida Urbana na Baixa Idade Média. O Exemplo de Lisboa", Estudos Medievais 7 155-172.

I. Gonçalves (1995), "Uma Realização Urbanística Medieval: o Calcetamento da Rua Nova de Lisboa", in Estudos de Arte e História - Homenagem a Artur Nobre de Gusmão. Lisboa.

M. da Maia (1987), Dissertação, I-III parte), in J. França, Lisboa Pombalina e o Iluminismo. Lisboa, 311-326.

I. Moita, ed. (1983), Lisboa Quinhentista: a imagem e a vida da cidade. Lisboa.

H. Murteira (1999), Lisboa da Restauração às Luzes. Lisboa.

M. Murteira (1999), "Lisboa - O Iluminismo e a Cidade", in Lisboa - Utopias na Viragem do Milénio. Lisboa, 69-79.

C. Oliveira (1987), Lisboa em 1511. Sumário em que brevemente se contêm algumas coisas assim eclesiásticas como seculares que há na cidade de Lisboa (1551). Lisboa.

E. Oliveira (1885), Elementos para a História do Município de Lisboa. Lisboa.

P. Pereira (2006), "Lisboa Manuelina. Problemas de Conceito", Revista de História da Arte 4 43-55.

F. Pizarro Gómez (1987), "La jornada de Felipe III a Portugal en 1619 y la arquitectura efímera", in II Simpósio Luso-Espanhol de História da Arte. As Relações Artísticas entre Portugal e Espanha na Época dos Descobrimentos. Coimbra, 123-146.

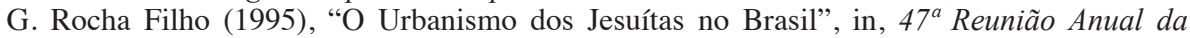
Sociedade Brasileira para o Progresso da Ciência. Universidade Federal do Maranhão, 1995.

W. Rossa (1999), “A cidade portuguesa”, in P. Pereira, coord., História da Arte Portuguesa. Lisboa. vol.3 232-323.

W. Rossa (2004), "Do plano de 1755-1758 para a Baixa-Chiado", in Monumentos. Lisboa.

A. Sanches (1756), Tratado de conservaçam da saude dos povos: obra util, e igualmente neseffaria aos Magiftrados, Capitaens Generaes, Capitaes de Mar, e Guerra, Prelados, Abbadeffas, Medicos, e Pays de familias. Paris.

A. Silva (1987), As Muralhas da Ribeira de Lisboa. Lisboa.

F. Silva (1750), Elogio funebre e historico do muito alto, poderoso, augusto, pio e fidelissimo Rey de Portugal, e Senhor D. João V. Lisboa.

J. Silva (2006), "Lisboa Medieval. Breves reflexões“, Revista de História da Arte 36.

M. Teixeira, M. Valla (1999), O Urbanismo Português, séculos XIII-XVIII. Portugal-Brasil. Lisboa. 